\title{
Heat Transfer Augmentation using Almond Dimple Tubes with Random Arrangement
}

\author{
Shiva K. Vyas ${ }^{\dagger *}$, Anand R. Nadgire ${ }^{\dagger}$, Brijesh S. Patil $^{\dagger}$ and Sachin R. Kale ${ }^{\dagger}$ \\ ${ }^{\dagger}$ Mechanical Engineering Department, SavitribaiPhule University Pune, MIT College of Engineering, Kothrud, Pune - 411038 (India)
}

Accepted 02 March 2016, Available online 15 March 2016, Special Issue-4 (March 2016)

\begin{abstract}
Objective of the present project work was to design, manufacture and evaluate the performance of a cross-flow heat exchanger using plain tube and almond dimple randomly arrangement. Air and Water were the fluids used to carry out test. The objective was to analyse the effect of gas flow over two different tubes. The mass flow rate of air was varied such that the Reynolds number was in between 10000 to 37000. Since the objective is to analyse the performance of gas flow over tubes, the tube side fluid flow condition was kept constant.. Comparisons of experimental results for Plain and almond tube when randomly arranged. The performance parameters related to heat exchanger such as pressure drop, overall heat transfer coefficient, heat duty have been reported in this work. Pressure drop found to be more in case of almond dimple tubes when compare with plain tube.
\end{abstract}

Keywords: Heat exchanger, dimple tubes, cross flow heat exchanger.

\section{Introduction}

Energy and materials saving considerations, as well as economic incentives, have led to efforts to produce more efficient heat exchange equipment. Common thermo-hydraulic goals are to reduce the size of a heat exchanger required for a specified heat duty, to upgrade the capacity of an existing heat exchanger, to reduce the approach temperature difference for the process streams, or to reduce the pumping power. Heat exchangers were initially developed to use plain (or smooth) heat transfer surfaces. An Enhanced heat transfer surface has a special surface geometry that provides a higher thermal performance, per unit base surface area than a plain surface.

The study of improved heat transfer performance is referred to as heat transfer augmentation, enhancement, or intensification. In general, this means an increase in heat transfer coefficient. Attempts to increase "normal" heat transfer coefficients have been recorded for more than a century, and there is a large store of information. The subject of "enhanced" heat transfer has become much more important to industry with progressing time. Uses of relatively complex geometries were initially limited by manufacturing process.

High heat transfer rates are obtained by the employing dimple tubes. This is an important development for the energy conversion and process industries. Use of Dimple tubes provides more heat transfer and an earlier transition to high heat transfer.

*Corresponding author: Shiva K. Vyas
The enhanced structure for both the Almond and spherical dimple could disturb, swirl, break the boundary layer developing, and augment the mixing of the hot and cold fluid and then improve the heat transfer of the tubes. Almond Dimpled tube picture is shown in below

\section{Literature Review}

Numerical studies for each tube, covering a wide range of Reynolds numbers starting from 1000 and going as far as 5000 was carried out by $\mathrm{K}$ Senthil Kumar. According to Nopparat the air side heat transfer performance is augmented approximately $10-22 \%$ at all Reynolds Numbers and all dimple arrangements. For staggered arrangements, the dimples pitch of $\mathrm{SL} / \mathrm{D}_{\text {minor }} 1 / 41.875$ and $\mathrm{ST} / \mathrm{D}_{\text {minor }} 1 / 41.875$ yields the optimum thermal resistance values of about $21.7 \%$ better than flat plate. For the staggered configuration of the dimple and compare with the results of Plain tube, numerical investigation was carried out for similar experimental conditions with addition to align array of dimple. Effect of the twisted tape insertion on heat transfer and flow friction characteristics in a concentric double pipe heat exchanger have been studied experimentally by using twisted tape placed inside the inner test tube of the heat exchanger with different twist ratios.

\section{Parameter of air-water heat exchanger}

Here the working fluid is air, which is flowing over the tubes in shell side of the heat exchanger and water flowing inside the tubes. By taking air side Reynolds 
number 10000 to 40000 ) the air-water heat exchanger configuration is selected as mentioned in following table.

Table 1Parameters of air-water heat exchanger

\begin{tabular}{|c|c|}
\hline Tube ID & $0.0316 \mathrm{~m}$ \\
\hline Thickness & $0.00325 \mathrm{~m}$ \\
\hline Tube OD & $0.0381 \mathrm{~m}$ \\
\hline Number of tubes & 12 nos. \\
\hline Rows & 4 nos. \\
\hline Columns & 3 nos. \\
\hline Tube length & $375 \mathrm{~mm}$ \\
\hline Transverse Pitch & $57.15 \mathrm{~mm}$ \\
\hline Longitudinal Pitch & $57.15 \mathrm{~mm}$ \\
\hline $\begin{array}{c}\text { Gap between last tube and } \\
\text { wall of heat exchanger }\end{array}$ & $10 \mathrm{~mm}$ \\
\hline Box Dimension & \\
\hline Length & $280 \mathrm{~mm}$ \\
\hline Height & $175 \mathrm{~mm}$ \\
\hline Width & $375 \mathrm{~mm}$ \\
\hline Hydraulic Diameter & $300 \mathrm{~mm}$ \\
\hline
\end{tabular}

Arrangement of dimple on tubes is explained in Table 2

Table 2 Arrangement of Dimple tubes

\begin{tabular}{|c|c|c|}
\hline Tube No & Wide End & Narrow End \\
\hline 1 & A & $\mathrm{B}$ \\
\hline 2 & B & A \\
\hline 3 & A & B \\
\hline 4 & B & A \\
\hline 5 & B & A \\
\hline 6 & A & B \\
\hline 7 & A & $\mathrm{B}$ \\
\hline 8 & A & B \\
\hline 9 & A & B \\
\hline 10 & $\mathrm{~B}$ & $\mathrm{~A}$ \\
\hline 11 & B & $\mathrm{A}$ \\
\hline 12 & $\mathrm{~B}$ & $\mathrm{~A}$ \\
\hline$\stackrel{\text { A Side }}{\longrightarrow}$ & $\begin{array}{c}\text { Heat } \\
\text { Exchanger }\end{array}$ & B side \\
\hline
\end{tabular}

\section{Experimentation}

Fig.1. shows the experimental setup. Experimental setup consists of horizontal air flow bench which is capable of providing air at different flow rates using VFD.

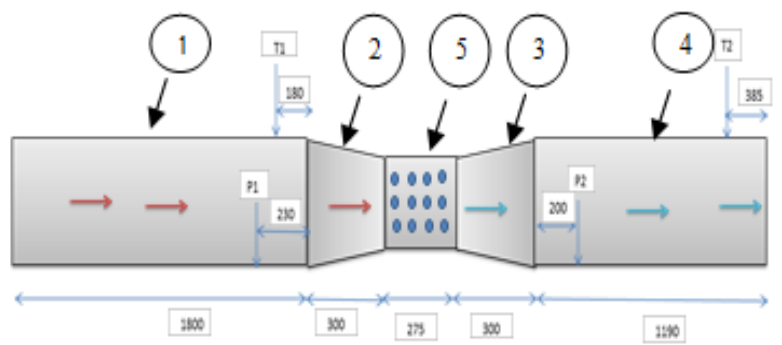

Fig.1 Experimental Setup

$\mathrm{T}_{1}=$ Inlet air temperature measurement,

$\mathrm{T}_{2}=$ Exit air temperature measurement

Label 5 indicates Heat Exchanger

\section{Experimental procedure}

1. Note down the water level inside the U- tube Manometer \& Check the inlet temperature of water.

2. Turn on the fan and adjust the required flow rate using VFD.

3. Le the flow get stabilised for 5 minutes \& note down the pressure drop readings.

4. Now turn on the heater. At the same time open the valve to allow water to flow through tubes.

5. Start taking temperature readings at water inlet \& exit and air inlet \& exit till constant readings are obtained (steady state is achieved).

6. Repeat the above procedure for different air flow rates.

\section{Results and Discussion}

\subsection{Comparison between Experimental and theoretical values}

The experimental results are compared with theoretical results using correlations and found good agreement between them. (Refer Table 3)

Table 3 Experimental and theoretical values of overall heat transfer coefficient for plain tube

\begin{tabular}{|c|c|c|}
\hline \multirow{2}{*}{$\begin{array}{c}\text { Air side } \\
\text { Reynolds } \\
\text { number }\end{array}$} & $\begin{array}{c}\text { Overall heat transfer co-efficient } \\
\text { for Plain Tube }\left(\mathbf{w} / \mathbf{m}^{\mathbf{2}} \mathbf{K}\right)\end{array}$ \\
\cline { 2 - 3 } & Experimental & Theoretical \\
\hline 10000 & 45.54 & 54.00 \\
\hline 20000 & 51.00 & 62.00 \\
\hline 28000 & 68.25 & 72.56 \\
\hline 37000 & 74.00 & 77.30 \\
\hline
\end{tabular}

\subsection{Comparison of overall heat transfer coefficient}

We can infer from the Fig.2 that overall heat transfer coefficient for Plain Tube is less than Dimple tubes.The main reason for the heat transfer enhancement is almond shapes on tube wall surface further increase the turbulent mixing in the flow near the wall by producing multiple vortex pairs, which enhance the turbulent flow heat transfer from the wall. 


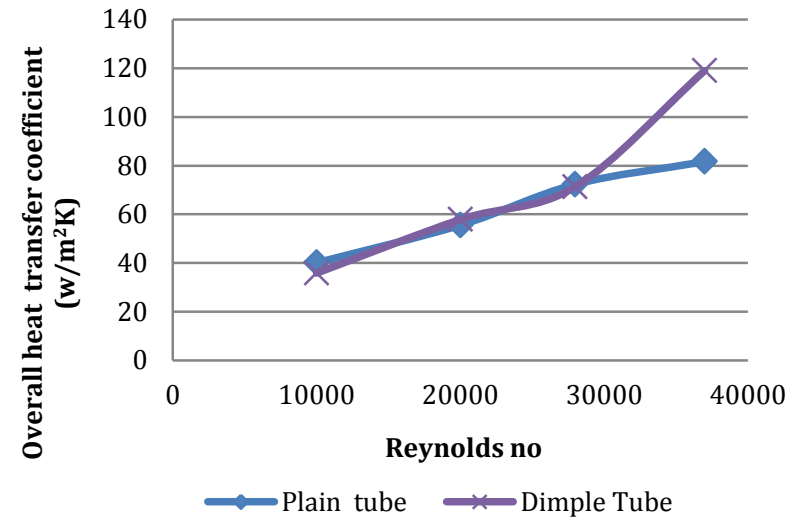

Fig.2 Overall heat transfer coefficient of plain \& dimple tube

\subsection{Comparison of Pressure Drop:}

From Fig.3 it can be seen that as the Reynolds no increases there is increase in the pressure drop. We can infer from the Fig.3 that pressure drop in plain tube is less than dimple tube.

Almonddimple shapes on tube wall surface further increase the turbulent mixing in the flow near the wall and produce multiple vortex pairs, which enhance the turbulent flow and thus there is increase of pressure drop is observed.

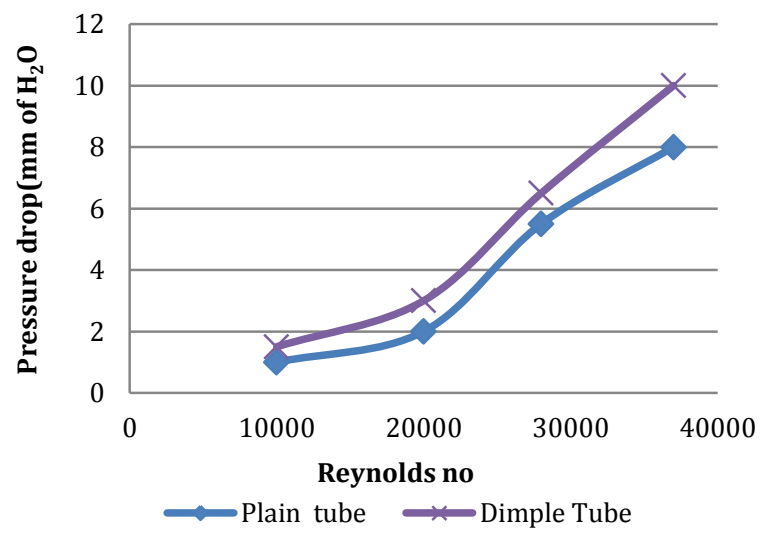

Fig.3 Pressure drop for plain \& dimple tube

\subsection{Comparison of Heat Loss}

We can infer from the Fig.4 that heat loss for plain tube is more than dimple tube when dimples are aligned left as well as right. From the Fig.4 we can conclude that heat losses are less for dimple tube as compared to plain tube. There is more turbulent mixing due to the vortices formed from secondary flows for almond dimple tubes which enhances the heat transfer coefficient and thus results in less heat loss.

\section{Conclusions}

An investigation was carried evaluate the performance of the cross-flow heat exchanger using plain and almond dimple tubes. Based on the results obtained from the analysis, the following conclusions have been drawn out.

1) The overall heat transfer co-efficient is found to increase while using almond shaped dimpled tubes over plain tubes, which is more pronounced at higher Reynolds number.

2) Pressure drop in case of almond dimple tubes is more as compared to plain tube, due to more turbulence.

3) Heat loss is less in case of dimple tubes as compare to Plain tubes this is due to there is more turbulent mixing due to the vortices formed from secondary flows for almond dimple tubes which enhances the heat transfer coefficient and thus results in reduction in heat loss.

\section{Acknowledgment}

Thanks to Mr. P. Charles, Head of ORC Dept. in Thermax India Ltd. for giving the opportunity to work on this challenging topic.

\section{References}

Antony-loci. A et al.(2011), Flow Analysis and Characteristics Comparison of Double Pipe Heat Exchanger Using Enhanced Tubes, IOSR Journal of Mechanical and Civil Engineering (IOSR-JMCE), e-ISSN:2278-1684, p-ISSN:2320334X, pp.16-21

Xuedong Wu et al. (2004), Numerical Study on the Effect of Tube Rows on the Heat Transfer Characteristic of Dimpled Fin, Hindawi Publishing Corporation Advances in Mechanical Engineering, Vol.-2014, Article ID: 637052, pp.1-9.

Pooja Patil et al. (2014), An Experimental Study of Heat Transfer Enhancement in the Circular Channel with Almond Shape Dimples, IOSR Journal of Mechanical and Civil Engineering (IOSR-JMCE), Vol.-11,Issue-5 Ver.-I, pp.4857

Watcharin Noothong et al. (2006), Effect of Twisted-tape Inserts on Heat Transfer in a Tube, The2ndJoint International Conference on 'Sustainable Energy and Environment', pp.1-5

K Senthil Kumar et al, Numerical Study of a Concentric Tube Heat Exchanger Using Dimpled Tubes with $\mathrm{Al}_{2} \mathrm{O}_{3}$ Nano Fluid Australian Journal of Basic and Applied Sciences, pp.185-195.

Raju R. Yenare et al. (2014), Experimental Study for Heat Transfer Enhancement Due To Surface Roughness at Laminar Flow, Int. Journal of Engineering Research and Applications, ISSN:2248-9622, Vol.-4, Issue-3 (Ver.-1), pp.239-243 